\title{
ANALISIS PENGENDALIAN PERSEDIAAN BAHAN BAKU PLAT BESI INDUSTRI KAROSERI MENGGUNAKAN METODE EOQ (Studi Kasus Pada PT. MISITAMA)
}

\author{
${ }^{1}$ Paduloh, ${ }^{2}$ Rio Prasetyo \\ ${ }^{1,2,}$ Program Studi Teknik Industri \\ Universitas Bhayangkara Jakarta Raya \\ Email : paduloh@dsn.ubharajaya.ac.id
}

\begin{abstract}
A b s trak
This study aims to analyze the optimal usage volume of iron raw plates required by PT. Misitama for the period of 2017. PT. Misitama is a company engaged in the field of tank manufacturing industry for the needs of manufacturing and mining industries. The study analyzed the total cost of Iron Iron raw material supply which must be used by PT. Misitama during 2017, analyzing reorder point, safety stock and raw material inventory control using EOQ method. The data used is the data of September 2017 - October 2017. The data used is secondary data derived from corporate data. The results show that the amount of raw material purchases during 2017 if using the EOQ method becomes lower. The optimal purchase of raw materials to be done by the company in 2017 is $14.8 \mathrm{~m} 2$ with the frequency of ordering to be done as much as 8 times. The quantity of safety stock (Safety Stock) that must be available in warehouse of $7 \mathrm{~m} 2$ and reorder point (reorder point) EOQ that is when the warehouse inventory is only $8.88 \mathrm{~m} 2$. Total inventory cost for production process issued by PT. Misitama by using EOQ method becomes smaller than the total cost of previous inventory.
\end{abstract}

Kata Kunci : Inventory, Raw Materials, Economic Order Quantity (EOQ), Industrial Body

\section{PENDAHULUAN}

PT. MISITAMA pada awal pendirian berbentuk CV. Kemudian berubah menjadi PT. Pada tahun 2012. Perusahaan berlokasi Di Jl. Kh. Muchtar Thabrani No. 3 Kaliabang Nangka Perwira Kec. Bekasi Utara Kota Bekasi. Perusahaan memproduksi dan mensuplai kebutuhan di dunia pertambangan yaitu diantara nya memproduksi Water truck, Fuel Truck dan Lube Truck. karoseri ini juga mampu memproduksi alat alat spesial project sesuai permintaan dari costumer. Bahan baku produksi adalah lembaran (Plat) besi yang kemudian di proses menjadi tangki.

Saat ini Asean menyerap sekitar 4,2\% dari total penjualan otomotif dunia, atau sekitar 3.549.506 unit Pangsa Asean pada 2013 inipun tak berbeda jauh dari tahun sebelumnya. Pada 2012, saat penjualan otomotif dunia mencapai 82,18 juta unit, negara-negara Asean menyerap sekitar 3,47 juta unit lembaga tersebut meyakini pasar Asean, khususnya Indonesia, kelak berperan dalam memassarkan produk otomotif teknologi ramah lingkungan. Sedangkan saat ini, berdasarkan data yang dirilis Fourin, penjualan unit mobil teknologi ramah ling kungan seperti hybrid electric vehicle (HEV) dan Electric Vehicle (EV) di level Asean hanya mencapai 0,6-0,9\% per tahun dari total penjualan level Asean.[1]

Bahan baku (Raw Material) merupakan prioritas utama dan sangat vital bagi suatu industri dalam proses produksinya. Hal ini menjadikan banyak perusahaan melakukan berbagai metode untuk mengelola persediaan bahan baku. Untuk melaksanakan pengadaan bahan baku yang diperlukan dalam proses produksi, perusahaan perlu mengadakan pembeliaan bahan baku. Prosedur dan cara pembelian bahan baku yang baik dan sesuai dengan kondisi perusahaan akan sangat menunjang kegiatan produksi. Maka dari itu perusahaan harus menentukan jumlah bahan bakuyang optimal dengan maksud agar jumlah pembelian dapat mencapai biaya persediaan minimum [2] 
Economic Order Quantity yaitu suatu pendekatan matematik yang menentukan jumlah barang yang harus dipesan untuk memenuhi permintaan yang diproyeksikan, dengan biaya persediaan yang diminimalkan [3]

Bahan baku Matrial yang digunakan PT. Misitama ada beberapa macam, Diantaranya Plat $6 \mathrm{~mm}$ polos, plat $2 \mathrm{~mm}$ polos, $3 \mathrm{~mm}$ polos $8 \mathrm{~mm}, 10 \mathrm{~mm} 12 \mathrm{~mm} 20 \mathrm{~mm}$, plat $4 \mathrm{~mm}$ kembang plat $6 \mathrm{~mm}$ kembang bodres, Plat Lembaran bordes lebih malah di bandingkan dengan plat polos biasa. Dan juga semakin tebal plat maka harga nya semakin mahal.

Selama ini PT Misitama dalam kebijaksanaan pengadaan bahan baku hanya berdasarkan pada pengalaman atau data-data dari masa lalu, jadi belum menerapkan manajemen atau analisis dengan menggunakan metode Economic Order Quantity dalam penanganan masalah pengendalian persediaan yang terjadi pada perusahaan PT Misitama. Untuk itu berdasarkan latar belakang maka peneliti ingin membantu perusahaan dalam penanganan masalah pengendalian persediaan bahan bakunya dengan menggunakan pendekatan metode Economic Order Quantity.

Menyikapi kondisi ini industri Karoseri harus memiliki strategi yang tepat dalam menjaga kelanjutan proses produksinya. Industri Karoseri harus dapat mempertahankan kondisi dimana bahan baku Plat besi tetap dalam kondisi yang stabil khususnya dari segi jumlah. Agar proses produksi dapat berlangsung secara berkesinambungan, maka industri harus dapat memperkirakan seberapa besar kebutuhan bahan baku Matrial Plat besi yang diperlukan di masa yang akan datang.

\section{METODE PENELITIAN}

Jenis dan pengumpulan data yang digunakan dalam penelitian ini adalah data primer dan data sekunder. Data primer merupakan data yang langsung di dapatkan dari perusahaan, sedangkan data sekunder merupakan data yang telah tersusun dalam bentuk dokumen tertulis yang diperoleh dari perusahaan, dan sumber sumber materi dari buku serta internet.

\section{HASIL DAN PEMBAHASAN}

\section{Analisa Persediaan Bahan Baku Menurut Metode EOQ}

Perusahaan melakukan pembelian bahan baku 1 (satu) kali per 1 (satu) bulan, dengan alasan bagaiman adanya orderan pembuatan tangki dalam proses produksi dan untuk mengantisipasi adanya kelangkaan bahan baku serta kenaikan harga bahan baku.

Berikut ini tabel jumlah Pembelian dan penggunaan bahan baku Bulan September - October tahun 2017:

Tabel 1. Data Pembelian dan Penggunaan PT. Misitama Bulan September-Oktober 2017

\begin{tabular}{|l|l|r|r|r|}
\hline No & \multicolumn{1}{|c|}{ Bulan } & $\begin{array}{c}\text { Pembelian } \\
\left(\mathrm{m}^{2}\right)\end{array}$ & $\begin{array}{c}\text { Pengguanaan } \\
\left(\mathrm{m}^{2}\right)\end{array}$ & \multicolumn{1}{c|}{$-/+$} \\
\hline 1 & Januari & 9 & 9 & 0 \\
\hline 2 & Februari & 7 & 9 & -2 \\
\hline 3 & Maret & 10 & 9 & 1 \\
\hline 4 & April & 9 & 12 & 3 \\
\hline 5 & Mei & 8 & 9 & -1 \\
\hline 6 & Juni & 7 & 10 & -3 \\
\hline 7 & Juli & 9 & 9 & 0 \\
\hline 8 & Agustus & 9 & 9 & 0 \\
\hline 9 & September & 12 & 9 & 3 \\
\hline 10 & Oktober & 10 & 9 & 0 \\
\hline 11 & November & 11 & 9 & -2 \\
\hline 12 & Desember & 7 & 9.41 & 0.08 \\
\hline Jumlah & & 108 & & 1 \\
\hline Rata rata & & 9.00 & & 9 \\
\hline
\end{tabular}

Sumber: PT. Misitama

Dari tabel 4.1 dapat disimpulkan bahwa penggunaan bahan baku Plat besi lebih besar dari pada pembelian bahan baku bulan September - Oktober tahun 2017. Penggunaan bahan baku Plat Besi meningkat dikarenakan permintaan karena naiknya harga batu bara dan hasil pertambangan lain nya. Sehingga pemesanan unit tangki ke misitama meningkat. Penggunaan bahan baku tahun 2017 sebanyak $113 \mathrm{~m}^{2}$. Frekuensi pembelian selama September - October tahun 2017 sebanyak 12

JIM, Vol. 3, No. 1, Januari 2018, pp.37-44 
kali,karena setiap 1 bulan sekali perusahaan membeli bahan baku. Untuk pembelian rata-rata Plat Besi selama bulan September - Oktober tahun 2017 adalah sebesar $9.0 \mathrm{~m}^{2}$

\section{A. Biaya Pemesanan}

Biaya pemesanan yaitu biaya yang dikeluarkan berkenaan dengan diadakannya pemesanan bahan baku dari supplier. Biaya pemesanan setiap kali dilakukan pemesanan terdiri dari biaya telepon, biaya transportasi dan pembongkaran, dan biaya administrasi.

Tabel 2. Biaya Pemesanan Bahan Baku Plat Besi PT. Misitama

\begin{tabular}{|c|l|c|}
\hline No & \multicolumn{1}{|c|}{ Jenis Biaya } & $(\mathrm{Rp})$ \\
\hline 1 & Biaya telpon & 300.000 \\
\hline 2 & $\begin{array}{l}\text { Biaya Transportasi dan } \\
\text { Pembongkaran }\end{array}$ & 1.200 .000 \\
\hline 3 & Biaya Administrasi & 50.000 \\
\hline & \multicolumn{1}{|c|}{ Jumlah } & 1.550 .000 \\
\hline
\end{tabular}

Untuk biaya yang dikeluarkan perusahaan pada setiap kali pemesanan adalah sebesar Rp. 129.000

\section{B. Biaya Penyimpanan}

Biaya penyimpanan adalah biaya - biaya yang dikeluarkan karena perusahaan melakukan penyimpanan dalam persediaan bahan baku dalam jangka waktu tertentu. Biaya penyimpanan yang dikeluarkan oleh PT. Misitama yaitu biaya pemeliharaan dan biaya kerusakan.

Tabel 3 Biaya Penyimpanan Per Unit Bahan Baku Plat Besi PT. Misitama Tahun 2017

\begin{tabular}{|c|l|r|}
\hline No & \multicolumn{1}{|c|}{ Jenis Biaya } & \multicolumn{1}{c|}{$(\mathrm{Rp})$} \\
\hline 1 & Biaya Pemeliharaan & 5.000 .000 \\
\hline 2 & Biaya Kerusakan & 10.000 .000 \\
\hline Jumlah (Rp) & 15.000 .000 \\
\hline $\mathrm{Rp} / \mathrm{m}^{2}$ & 132.743 \\
\hline
\end{tabular}

Terlihat pada tabel 3 bahwa terdapat dua jenis biaya penyimpanan, yaitu biaya pemeliharaan dan biaya kerusakan.Untuk biaya penyimpanan per unit yang dikeluarkan PT. Misitama adalah sesbesar Rp. 13.274 / $\mathrm{m}^{2}$.

\section{Analisis Data}

\section{A. Perhitungan EOQ}

Jumlah penggunaan bahan baku Plat Besi, harga bahan baku Plat Besi per $\mathrm{m}^{2}$, besarnya biaya pemesanan setiap kali melakukan pemesanan dan besarnya biaya penyimpanan per unit $\left(\mathrm{m}^{2}\right)$ pada PT. Misitama periode tahun 2017 dapat dilihat pada tabel 4.

Tabel 4 Penggunaan bahan Baku Material Plate, Harga Per Unit,Total Biaya Penggunaan, Biaya Pemesanan,dan Biaya Penyimpanan Per Periode 2017

\begin{tabular}{|l|r|}
\hline \multicolumn{1}{|c|}{ Uraian } & \multicolumn{1}{|c|}{$\mathbf{2 0 1 7}$} \\
\hline Kuantitas $\left(\mathrm{M}^{2}\right)$ & 113 \\
\hline Harga $\left(\mathrm{Rp} / \mathrm{M}^{2}\right)$ & 1.000 .000 \\
\hline Biaya Total $(\mathrm{Rp})$ & 113.000 .000 \\
\hline Biaya Pemesanan Setiap Kali Pesan $(\mathrm{Rp})$ & 129.000 \\
\hline Biaya Penyimpanan $\left(\mathrm{Rp} / \mathrm{M}^{2}\right)$ & 132.743 \\
\hline
\end{tabular}

Dari tabel 4 dapat dihitung kuantitas pembelian optimal.

$$
E O Q=\sqrt{\frac{2 S D}{H}}
$$

Dimana:

$\boldsymbol{E} \boldsymbol{O Q}=$ Kuantitas pemesanan optimal $\left(\mathrm{m}^{3}\right)$.

$\mathbf{D}=$ kuantitas Penggunaan per periode ( $\mathrm{m}^{3} /$ tahun).

$\mathbf{S}=$ biaya per pesanan $\left(\mathrm{Rp} / \mathrm{m}^{3}\right)$.

$\mathbf{H}=$ biaya penyimpanan per unit per periode ( $\mathrm{Rp} / \mathrm{m}^{\mathrm{w}}$ tahun $)$. 
Sehingga jumlah pembelian bahan baku Plat Besi yang optimal setiap kali pesan pada tahun 2017 sebesar $14,8 \mathrm{~m}^{2}$, dengan frekuensi pembelian bahan baku yang diperlukan PT Misitama adalah sebanyak 8 kali.

\section{B. Penentuan Persediaan Pengaman (Safety Stock)}

Safety stock atau persediaan pengaman adalah persediaan untuk mengantisipasi Unsur ketidakpastian permintaan dan penyediaan. Apabila, persediaan pengaman tidak mampu mengantisipasi ketidakpastian tersebut, akan terjadi kekurangan persediaan (stockout). Penentuan jumlah persediaan pengaman dapat dilakukan dengan membandingkan pemakaian bahan baku kemudian dicari berapa standar deviasinya. Setelah diketahui berapa besarnya standar deviasi maka akan ditetapkan besarnya analisis penyimpangan. Dalam analisis penyimpangan ini management perusahaan menentukan seberapa jauh bahan baku yang masih dapat diterima. Pada umumnya batas toleransi yang digunakan adalah $5 \%$ diatas perkiraan dan $5 \%$ dibawah perkiraan dengan nilai 1,65. Untuk perhitungan standar deviasi dapat dilihat pada tabel 4.5 berikut.

Tabel 5. Standar Deviasi Bulan September-Oktober Tahun 2017

\begin{tabular}{|c|l|c|c|c|}
\hline No & \multicolumn{1}{|c|}{ Bulan } & $\begin{array}{c}\text { Penggunaan } \\
\left(\mathrm{m}^{2)}\right.\end{array}$ & $\begin{array}{c}\text { Deviasi } \\
(\mathrm{x}-\overline{\mathrm{x}})\end{array}$ & $\begin{array}{c}\text { Kuadrat } \\
(\mathrm{x}-\overline{\mathrm{x}})^{2}\end{array}$ \\
\hline 1 & Januari & 9 & 0.41 & 0.1681 \\
\hline 2 & Februari & 9 & 0.41 & 0.1681 \\
\hline 3 & Maret & 9 & 0.41 & 0.1681 \\
\hline 4 & April & 12 & 2.59 & 6.7 \\
\hline 5 & Mei & 9 & 0.41 & 0.1681 \\
\hline 6 & Juni & 10 & 0.59 & 0.3481 \\
\hline 7 & Juli & 9 & 0.41 & 0.1681 \\
\hline 8 & Agustus & 9 & 0.41 & 0.1681 \\
\hline 9 & September & 9 & 0.41 & 0.1681 \\
\hline 10 & Oktober & 10 & 0.59 & 0.3481 \\
\hline 11 & November & 9 & 0.41 & 0.1681 \\
\hline 12 & Desember & 9 & 0.41 & 0.1681 \\
\hline Jum & & 113 & 7.46 & 8.9091 \\
\hline Rata rata & 9.41 & & \\
\hline
\end{tabular}

Dari tabel 4.5 diketahui bahwa standar deviasi yang diperoleh adalah sebesar 4.24 sehingga diperoleh besarnya kuantitas persediaan pengaman (Safety Stock) optimal yang harus tersedia di gudang adalah sebesar $7 \mathrm{~m}^{2}$

\section{Penentuan Pemesanan Kembali (Reorder Point)}

Saat pemesanan kembali atau Reorder Point adalah saat dimana perusahaan harus melakukan pemesanan bahan baku kembali, sehingga penerimaan bahan baku yang dipesan dapat tepat waktu. Untuk menentukan kapan pemesanan dilakukan, maka digunakan rumus sebagai berikut :

$\boldsymbol{R O P}=$ Safety Stock $+($ Lead Time $x \mathrm{Q})$

Dimana:

$\boldsymbol{R O P}=$ Titik pemesanan kembali

Lead time $=$ Waktu tunggu (Hari).

Safety stock $=$ Persediaan pengaman $\left(\mathrm{m}^{3}\right)$.

$\mathbf{Q}=$ Penggunaan bahan baku rata-rata per hari $\left(\mathrm{m}^{3} /\right.$ hari $)$

Diketahui bahwa selisih waktu antara pemesanan dengan penerimaan bahan baku (lead time) adalah 5 hari, dan besarnya safety stock $7 \mathrm{~m}^{2}$ jumlah penggunaan bahan baku adalah sebesar 9,41 $\mathrm{m}^{2}$, dan penggunaan bahan baku rata-rata perhari adalah sebesar $0,376 \mathrm{~m}^{3}$. Sehingga ROP : $7+(5 \times 0.376)=8.88$ Sehingga tahun 2017 PT. Misitama melakukan pemesanan kembali pada saat persediaan bahan baku digudang sisa $8.88 \mathrm{~m}^{2}$

\section{Penentuan Persediaan Maksimum (Maximum Inventory)}

JIM, Vol. 3, No. 1, Januari 2018, pp.37-44 
Persediaan maksimum diperlukan oleh perusahaan agar jumlah persediaan yang ada digudang tidak berlebihan sehingga tidak terjadi pemborosan modal kerja. Adapun untuk mengetahui besarnya persediaan maksimum dapat digunakan rumus :

Maximum Inventory = Safety Stock + EOQ

Safety Stock $=7 \mathrm{~m}^{2}$

$E O Q=8.1 \mathrm{~m}^{2}$

Persediaan Maksimum $=7 \mathrm{~m}^{2}+8.1 \mathrm{~m}^{2}$

$=15.1 \mathrm{~m}^{2}$

Untuk mengetahui lebih jelas mengenai perhitungan persediaan bahan baku Plat Besi pada PT. Misitama dengan menggunakan metode EOQ selama periode tahun 2017 dapat dilihat pada tabel 6.

Tabel 6. Hasil perhitungan besarnya EOQ, Safety Stock, Reorder Point, dan Maximum Inventory Bahan Baku Matrial Besi Periode tahun 2017

\begin{tabular}{|c|c|c|}
\hline No & Uraian & $\mathbf{2 0 1 7}$ \\
\hline 1 & EOQ & $8.1 \mathrm{~m}^{2}$ \\
\hline 2 & Safety Stock & $7 \mathrm{~m}^{2}$ \\
\hline 3 & ROP & $8.88 \mathrm{~m}^{2}$ \\
\hline 4 & Maximum inventory & $15.1 \mathrm{~m}^{2}$ \\
\hline
\end{tabular}

\section{E. Perhitungan Biaya Total Persediaan (Total Inventory Cost)}

Perusahaan dengan menggunakan perhitungan EOQ. Hal ini dilakukan untuk penghematan biaya persediaan perusahaan. Untuk menghitung total biaya persediaan digunakan rumus sebagai berikut :

$\mathrm{TIC}=\frac{D}{Q}(S)+\frac{Q}{2}(\mathbf{H})$

Dimana:

D = Kuantitas Penggunaan per periode $\left(\mathrm{m}^{2} /\right.$ tahun $)$.

$\mathbf{S}=$ Biaya per pesanan (Rp/tahun).

$\mathbf{H}=$ Biaya penyimpanan per unit $\left(\mathrm{Rp} / \mathrm{m}^{2} /\right.$ tahun $)$.

$\mathrm{Q}=$ Unit yang dipesan per order

Total biaya persediaan yang dikeluarkan PT. Misitama menurut metode $E O Q$ pada tahun 2017 adalah sebesar Rp. 111.984.932 Sedangkan untuk perhitungan total biaya persediaan dari PT.Misitama akan dihitung menggunakan persediaan rata-rata yang ada di perusahaan dengan menggunkan rumus sebagai berikut :

TIC $=($ Penggunaan rata-rata $)(H)+(S)(F)$

\section{Dimana:}

$\mathrm{H}=$ Biaya penyimpanan per unit $\left(\mathrm{Rp} / \mathrm{m}^{3} / \mathrm{thn}\right)$.

$\mathrm{S}=$ Biaya pemesanan per pesanan $\left(\mathrm{Rp} / \mathrm{m}^{3}\right)$.

\section{F= Frekuensi pembelian yang dilakukan Perusahaan}

Sehingga diperoleh total biaya persediaan yang dikeluarkan PT. Misitama pada tahun 2017 adalah sebesar Rp. 142.268.000,-

\section{F. Analisis Selisih Efisiensi Pemesanan Bahan Baku yang Optimal dengan Pemesanaan Bahan Baku yang dilakukan dengan Kebijakan PT. Misitama}

Dari hasil perhitungan yang telah dilakukan maka terlihat perbandingan persediaan bahan baku antara kebijakan perusahaan dengan kebijaksanaan pembelian dengan menggunakan metode $E O Q$, dapat dilihat dari jumlah pembelian optimal, frekuensi pembelian, total biaya persediaan, persediaan pengaman dan kapan seharusnya perusahaan memesan kembali bahan baku. Sehingga 
dapat mengetahui metode mana yang lebih efisien dalam penyediaan bahan baku. Berikut ini perbandingan antar penyediaan bahan baku menurut kebijakan perusahaan dan penyediaan menurut perhitungan metode Economic Order Quantity.

Tabel 7. Perbandingan persediaan bahan baku antara kebijakan perusahaan dengan kebijaksanaan pembelian dengan menggunakan metode $E O Q$

\begin{tabular}{|l|c|c|}
\hline \multicolumn{1}{|c|}{ Hal } & Kebijaksanaan Perusahaan & Metode EOQ \\
\hline Kuantitas Pembelian & $9.41 \mathrm{~m}^{2}$ & $\mathbf{1 4 . 8 \mathbf { m } ^ { 2 }}$ \\
\hline Frekuensi Pembelian & $12 \mathrm{kali}$ & $8 \mathrm{kali}$ \\
\hline Persediaan Pengaman & - & $7 \mathrm{~m}^{2}$ \\
\hline Titik Pemesanan Kembali & - & $8.88 \mathrm{~m}^{2}$ \\
\hline Persediaan Maksimum & - & $15.1 \mathrm{~m}^{2}$ \\
\hline Total Biaya Persediaan & Rp. 142.268 .000 & Rp. 111.984 .932 \\
\hline
\end{tabular}

Dapat diketahui Terdapat perbandingan antara kebijakan perusahaan dengan menggunakan metode EOQ .yaitu pada tahun 2017 menunjukkan PT.Misitama harus melakukan pembelian bahan pada saat persediaan sisa sebesar $8.88 \mathrm{~m}^{2}$. Dengan demikian pada saat bahan baku diterima dengan lead time 5 hari, persediaan yang tersisa masih $7 \mathrm{~m}^{2}$, dan untuk menghindari terjadinya kelebihan bahan baku, jumlah pembelian yang harus dilakukan sebesar $14,8 \mathrm{~m}^{2}$ agar tidak melebihi maximum inventory sebesar $15.1 \mathrm{~m}^{2}$ Total biaya persediaan bahan baku menurut metode $E O Q$ adalah sebesar Rp. 111.984.932,sedangkan total biaya persediaan bahan baku menurut PT. Misitama sebesar Rp. Rp. 142.268.000. Jadi terdapat penghematan sebesar Rp. 30.283.068.

Dari hasil tersebut terdapat penghematan total biaya persediaan karena total biaya yang dihitung menurut PT. Misitama lebih besar dari total biaya yang dihitung menurut metode $E O Q$.

\section{KESIMPULAN}

Berdasarkan hasil penelitian dan analisis data sebelumnya, maka dapat disimpulkan bahwa kebijakan pengadaan persediaan bahan baku yang Oleh PT. Misitma belum menunjukkan biaya yang minimum dalam arti biaya persediaannya masih lebih besar dibandingkan apabila perusahaan menggunakan metode $E O Q$. Dalam hal ini dapat dikemukakan kesimpulan sebagai berikut:

1. Pembelian bahan baku optimal tiap kali pesan menurut metode $E O Q$ adalah $14,8 \mathrm{~m}^{2}$ sedangkan menurutkebijakan perusahaan adalah $9.41 \mathrm{~m}^{3}$, sedangkan persediaan maksimum (Maximum Inventory) yang harus disediakan perusahaan meurut metode $E O Q$ adalah sebesar $15.1 \mathrm{~m}^{2} \mathrm{~m}^{3}$, sedangkan menurut kebijakan perusahaan tidak ada persediaan maksimum yang disediakan perusahaan.

2. Kuantitas persediaan pengaman ( safety stock) yang dibutuhkan perusahaan menurut metode $E O Q$ adalah $7 \mathrm{~m}^{2}$ sedangkan menurut kebijakan perusahaan tidak ada kuantitas pengaman.

3. Waktu pemesanan kembal ( re - order point), waktu yang tepat menurut metode $E O Q$ adalah pada saat persediaan bahan baku di dalam gudang masih $8.88 \mathrm{~m}^{2}$ sedangkan menurut kebijakan perusahaan tidak ada waktu pemesanan kembali atau reorder point. Frekuensi pembelian bahan baku optimal menurut metode $E O Q$ adalah 8 kali dalam setahun, sedangkan menurut kebijakan perusahaan adalah 12 kali.

4. Total biaya persediaan optimal selama satu tahun menurut metode EOQ sebesarRp. 111.984.932, sedangkan menurut kebijakan perusahaan sebesar Rp. . 111.984.932.

\section{SARAN}

Setelah Dilakukan perhitungan dan menganalisis masalah yang dihadap PT. Misitama, maka penulis mengajukan saran yang dapat dijadikan sebagai bahan pertimbangan dalam kebijakan pengadaan bahan baku. Adapun saran-saran itu adalah sebagai berikut:

1. Perusahaan perlu mengkaji kembali metode pengendalian yang diterapkan selama ini, karena berdasarkan hasil pengolahan dengan metode yang digunakan peneliti, total biaya persediaan masih dapat diminimalkan. Dengan menggunakan metode EOQ dalam kebijakan pengadaan bahan baku perusahaan akan mendapatkan kuantitas pembelian bahan baku yang optimal dengan biaya yang minimum dibandingkan kebijakan perusahaan sebelumnya. 
2. Perusahaan sebaiknya menentukan besarnya safety stock dan re-order point dalam pengendalian persediaan bahan baku untuk melindungi atau menjaga kemungkinan kekurangan bahan baku yang lebih besar dari perkiraan dan untuk menjaga kemungkinan keterlambatan bahan baku yang dipesan.

3. Dalam pengadaan bahan baku Plat Besi PT.Misitama sebaiknyamelakukan pembelian dalam jumlah yang besar dan dengan frekuensi yang rendah per periode produksi, hal ini dilakukan untuk meminimalisir biaya persediaan.

\section{DAFTAR PUSTAKA}

Kementrian Perindustrian Republik Indonesia,

2013.http://www.kemenperin.go.id/artikel/12844/Industri-Karoseri-Bus-Domestik-Dapat-Pesanan-1000Unit (online accessed: September 29th ,2017)

Asrori.H, 2010.Analisis Pengendalian Persediaan Bahan Baku Kayu Sengon PT. Abhirama Kresna Dengan Metode EOQ (skripsi) .Program Studi Manajemen Industri Fakultas Ekonomi Universitas Sebelas Maret Surakarta.

Fahmi, 2012.Manajemen Produksi dan Operasi. Penerbit: Alfabeta, Bandung.

Siwi M, 2010 . Analisis Pengendalian Persediaan Bahan Baku Dengan Metode EOQ Pada Produk Obat Anti Nyamuk Bakar Manguni(Jurnal). Jakarta.

Handoko, 2000.Dasar-dasar Manajemen Produksi dan Operasi. Penerbit: BPFE Yogyakarta.

Haming,Murdifin dan Mahfud Nurnajamuddin. 2012. Manajemen Produksi Modern (Operasi Manufaktur dan Jasa). Edisi Kedua Cetakan Pertama. Penerbit : PT Bumi Aksara. Jakarta.

Simbar, 2014.Analisis Sistem Pengadaan dan Pengendalian Persediaan Bahan Baku Jamu Tradisional Pada UD. Batu Zaman ., Universitas Sam Ratualngi, (Jurnal) Manado.

Kurniawan.W, 2008.Analisis Pengendalian Persediaan Bahan Baku di Perusahaan Kecap Segitiga Majalengka. Program Sarjana Ekstensi Manajemen Agribisnis, Fakultas Pertanian, Institut Pertanian Bogor.

Nasutioon, Arman Hakim, 2003. Perencanaan dan Pengendalian Produksi.Edisi Pertama. Surabaya : Guna Widya.

Prawirosentono, Suyadi 2007.Manajemen Operasi (operations management) analisis dan studi kasus.Edisi keempat, cetakan pertama. Bumi Aksara : Jakarta.

Indroprasto,Suryani, 2012. Analisis Pengendalian Produk Dengan Metode EOQ Menggunakan Algoritma Genetika Untuk Mengefisiensikan Biaya Persediaam .Fakultas Teknologi Informasi Institut Teknologi Sepuluh Nopember .

Ruauw,E. 2011. Pengendalian persediaan bahan baku(Contoh Pengendalian pada usaha Grenda Bakery Lianli (Jurnal). Manado.

Rumincap, D.J. 2010.Analisis Persediaan Bahan Baku pada Usaha Mikro Kecil Menengah (UMKM) (Studi Kasus Usaha. 
